Aim To characterise the patients who were seen between 1998 and 2011 with a diagnosis of PD.

Method Retrospective case notes review of 18 identified cases with history and signs consistent with PD.

Results The mean age of the 18 patients was 42 (range 20-63); six were Caucasians, six were from Indian subcontinent, five Africans and one Caribbean. All except one gave a history of change in penis shape during erection: six had upward curvature, seven bent to the left, one to the right, two had shortening of penis/distal flaccidity and one had no change. Seven had pain on erection, 10 had history of a penile lump, five had erectile dysfunction and two had difficulty in penetration. The mean duration of symptoms before presentation to the clinician was 64.1 months (range 3 weeks to 264 months), none had a history of penile trauma, intracavernosal injection or Dupuytren's contracture. Of four who had an ultrasound scan of the penis, two were confirmed to have lumps consistent with PD. Of 12 who had primary treatment with colchicine for 2-12 months; three showed improvement in symptoms, three no change and six unknown outcome. Of two who had primary treatment with pentoxifyline for 1-11 months one showed improvement in symptoms and one unknown. Of three who failed to respond to colchicine and were then treated with pentoxifyline, a further one showed improvement.

Conclusion (1). $28 \%$ of cases had ED. (2). Overall, $33 \%$ of the patients had symptomatic improvement with treatment and none had worsened post treatment which is consistent with the findings of other studies.

\section{P185 A PILOT PROGRAMME FOR THE UNDERGRADUATE TEACHING OF SEXUAL HEALTH USING INTERACTIVE DEMONSTRATION FOR EXPERIENTIAL LEARNING}

doi:10.1136/sextrans-2012-050601c.185

${ }^{1} \mathrm{~B}$ Flynn, ${ }^{*}{ }^{2} \mathrm{~F}$ Fernando, ${ }^{2} \mathrm{R}$ Cochrane, ${ }^{3} \mathrm{~K}$ Boyd, ${ }^{4} \mathrm{~B}$ Allan. ${ }^{1}$ Genito-Urinary Medicine, Chalmers sexual health centre, Edinburgh, UK; ${ }^{2}$ Chalmers sexual health centreEdinburgh, UK; ${ }^{3}$ Palliative Care Unit, RIE; ${ }^{4}$ Patient Co-ordinator, RIE

Background In Edinburgh in May 2011, the GUM and FP/SRH departments integrated. A priority for the new service was reviewing and improving the undergraduate teaching offered in sexual health.

Aim To increase and improve undergraduate teaching, using experiential learning to develop the skills and attitudes essential for managing patients with sexual health needs.

Methods An OSCE format with interactive demonstration was chosen as the method to achieve these aims. Stations focused on effective communication and developing appropriate skills and attitudes. Three OSCE stations, based on common and important sexual health scenarios, were designed for interactive group work using simulated patients. The fourth station facilitated open discussion of sexuality and its implications for the well-being of patients. Four pilot sessions were run. Feedback questionnaires were given to students, facilitators and simulated patients. Strengths, weaknesses, and suggestions for improvement were requested. Participants were asked to score their level of enjoyment (from 1 to 10). Students also scored the course on how useful it was in meeting their educational needs (see abstract P185 table 1).

Results Feedback was extremely positive. Students felt the opportunity to practice their communication skills within sexual health consultations in a risk-free environment was the main strength. A request for "more scenarios" was the most commonly cited "weakness" and main suggestion for improvement.

Conclusion Following this successful pilot, the programme will now be regularly provided to the undergraduate medical students of Edinburgh. A similar model of teaching could be achieved at other departments, and is a successful way of delivering experiential learning in teaching resource limited settings.

Abstract P185 Table 1 Participant evaluation of interactive demonstration for experiential learning

\begin{tabular}{llll}
\hline & Simulated patient & Facilitator & Student \\
\hline Number of returned forms & 12 & 25 & 75 \\
"Enjoyment" mean score (1-10) & 8 & 8 & 8 \\
"Useful" mean score (Students only) & & & 8 \\
\hline
\end{tabular}

\section{P186 SHOULD NURSING STAFF IN SEXUAL AND REPRODUCTIVE HEALTH (SRH) CLINICS WEAR A UNIFORM?}

doi:10.1136/sextrans-2012-050601c.186

C Cunningham, ${ }^{*}$ V Stewart, L Emslie, T Davis. NHS Tayside, Dundee, UK

Background The NHS Scotland dress code policy was implemented in 2008 with the introduction of a national uniform in 2010. Historically nursing staff within SRH clinics have chosen not to wear a uniform to create a less formal environment. Within the policy it is stated that boards should conduct a full risk assessment to ensure that local policy is appropriate for different categories of staff.

Aim To gather opinions from both patients and nursing staff about the impact of the introduction of the national uniform policy within the SRH service.

Methods A patient $(n=224)$ and nursing staff $(n=13)$ survey was undertaken over a 10-day period in January 2012.

Results The patient survey revealed that a minority (7\%) of patients preferred that nursing staff wore their own clothes with the majority (54\%) having no preference on staff dress code. The nursing staff surveys revealed that the majority work within a community health centre setting (46.2\%) and were moderately happy with wearing a uniform (30.8\%). Convenience was identified as a very important factor when choosing to wear a uniform $(53.8 \%)$. The majority of staff agreed or strongly agreed that wearing a uniform made them more approachable (46.2\%) and their role more identifiable to patients $(71.6 \%)$ but they neither agreed or disagreed that it increased a patient's perception of their competency (46.2\%) or enhanced professionalism (30.8\%).

Discussion Although there was concern that the introduction of uniforms for sexual health nursing staff might interfere with the nurse-patient relationship this has not be realised.

\section{P187 WORKFORCE PLANNING AND SAS DOCTORS: A CRISIS IN WAITING}

doi:10.1136/sextrans-2012-050601c.187

${ }^{1} \mathrm{~J}$ Lee, ${ }^{2} \mathrm{E}$ Carlin, ${ }^{3} \mathrm{~A}$ Robinson. ${ }^{1}$ Clayton Hospital; ${ }^{2}$ King's Mill Hospital, Nottinghamshire, UK; ${ }^{3}$ Mortimer Market Centre, London, UK

Background The importance of medical workforce planning is well recognised but it is an inexact science and has usually concentrated on consultant and trainee numbers. The difficulties in planning are complicated by a lack of information on specialty and associate specialist (SAS) doctors.

Aims We sought to aid workforce planning by collecting data from the SAS workforce to enable broader sexual health service planning.

Methods A survey monkey questionnaire was devised and sent to all SAS doctors in sexual health who were known to the British Association for Sexual Health and HIV (BASHH) or its members. 